\title{
RANCANG BANGUN WEB REPLIKA PADA WEBSITE E-COMMERCE
}

\author{
Baiq Dinasti Gita Purnama Putri, Anton Setiawan Honggowibowo, \\ Anggraini Kusumaningrum \\ Program Studi Teknik Informatika \\ Sekolah Tinggi Teknologi Adisutjipto Yogyakarta \\ informatika@stta.ac.id
}

\begin{abstract}
E-commerce or electronic commerce is an activity related to the purchase, sale, marketing of goods or services by using electronic systems such as the Internet or a computer network as a medium. In its development, e-commerce website has a lot of models and concepts, one of which is a replica website. Replica website is a reflection of the website host website itself Website replica would be obtained if it had been making purchases on the website of the parent (stta.name:8000) or web replica owned by a member (stta.name:8000/? sponsor=namaanggota). If you already have a replica website then the owner can sell online using the web replica, and can change the prices of goods as well as web background replicas. Besides being able to change the price and the background, a replica web owners are also entitled to a bonus from the purchase of its products downline level 1. For the award is the excess of the price that has been modified with an initial price of a web master or web links above. From the calculation of the questionnaire that was distributed to 30 respondents, the result of testing knowledge of web replica of $42.7 \%$ based on the assessment interval is Enough and application usage by 78.5\%, which means Good.
\end{abstract}

Keywords: E-Commerce, Master Website, Website Replication

\section{Pendahuluan}

Peningkatan penggunaan internet setiap harinya ternyata tidak diacuhkan begitu saja oleh para pelaku bisnis baik perorangan maupun perusahaan. Para pelaku bisnis justru memanfaatkan peningkatan penggunaan internet ini untuk mengembangkan jaringan bisnis. Kemajuan di bidang teknologi ini dirasakan sangat bermanfaat untuk dijadikan sebagai salah satu cara atau strategi pemasaran bisnis. Banyak para pelaku bisnis yang sengaja membuat website, blog atau bahkan fans page di jejaring sosial untuk memperkenalkan dan memasarkan produk. Melalui onlinemarketing, informasi produk dapat dengan mudah menjangkau konsumen yang ada jauh dari domisili usaha, tanpa harus terjun langsung ke daerah tersebut untuk mempromosikan produk. Salah satu metode bisnis yang sangat berkembang saat ini yaitu e-commerce.

Dalam perkembangannya websitee-commerce sudah banyak sekali model serta konsep yang ditawarkan oleh para pelaku bisnis web replika merupakan salah satu model dari website ecommerce. Penelitian ini mencoba merancang web replika pada website e-commerce. Web replika sendiri adalah salah satu alat promosi berupa websiteyang bisadigunakan dalam memasarkan dan mengembangkan bisnis e-commerce. Apa yang ditampilkan dalam webreplika sama seperti web induk karena pada dasarnya website replika merupakan cloning dari website induk itu sendiri. Pada web replika yang akan dirancang pemilik web replika dapat melakukan ubah harga dan ubah background pada web replika yang dimilikinya. Selain itu pemilik replika juga akan mendapatkan bonus dari pembelian produk oleh downline. 


\section{METODE PENELITIAN}

\subsection{E-commerce}

Definisi websitee-commerce secara umum "E-commerce is a dynamic set of technologies, applications, and business process that link enterprises, consumers, and communities through electronic transactions and the electronic exchange of goods, service and information"(Baum, 1999). Dari definisi tersebut dapat diartikan bahwa e-commerce merupakan satu set dinamis teknologi, aplikasi dan proses bisnis yang menghubungkan perusahaan, konsumen, dan komunitas tertentu melalui transaksi yang dilakukan secara elektronik dan perdagangan barang, pelayanan dan pemberian informasi yang juga dilakukan secara elektronik.

\subsection{WebReplika}

Website replika adalah website cerminan dari website induk itu sendiri. Secara fisik website replika dengan website induk menampilkan tampilan yang persis sama. Secara umum link pada suatu website replika biasanya terdiri dari domain website induk yang kemudian dibelakangnya diikuti dengan ID atau nama dari pengguna atau pemilik website replika tersebut. Jika menemukan alamat website seperti pada contoh dibawah ini maka dapat dipastikan website yang sedang dibuka tersebut adalah website replika. Contonya seperti ini :http:/www.domaininduk.com/?id=namapemilik.

\subsection{Perancangan Sistem}

\subsubsection{Diagram Konteks}

Diagram konteks dari Sistem Informasi E-commerce (online shop) yang terdiri dari 3 entity yaitu :

1. EntityADMIN.

2. EntityCUSTOMER.

3. Entity ANGGOTA

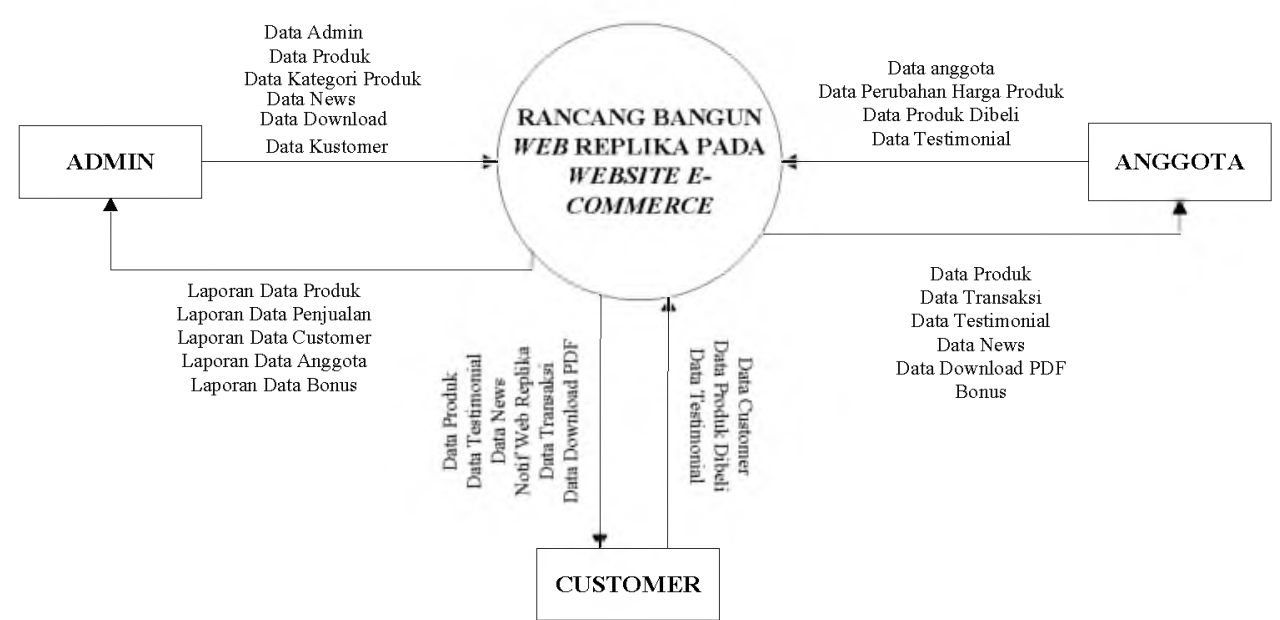

Gambar 1. Diagram Konteks Web Replika Pada WebsiteE-commerce.

\subsubsection{DFD Level 0}

Pada level 0 menunjukkan semua proses utama yang menyusun keseluruhan sistem. Adapun penjelasan dari masing-masing proses yang ada pada level 0 sebagai berikut:

1. Proses 1.0 yaitu proses registrasi, pada tahap pertama ini ialah tahap pendaftaran baik admin maupun customer untuk mendaftar.

2. Proses 2.0 P yaitu proses login bagi admin, customer maupun anggota.

3. Proses 3.0 yaitu data produk. Proses penginputan data produk oleh admin dan yang nantinya dapat dilihat oleh customer dan anggota pada online shop. 
4. Proses 4.0 yaitu data kategori. Proses penginputan kategori data produk.

5. Pada proses 5.0 yaitu data news. Penginputan berita oleh admin yang nantinya dapat dilihat oleh customer dan anggota pada online shop.

6. Proses 6.0 yaitu data download. Admin mengupload data PDF yang dapat didownload customer dan anggota.

7. Pada proses 7.0 P yaitu isi testimonial oleh customer, dan anggota.

8. Pada proses 8.0 yaitu proses data transaksi. Proses ini menjelaskan alur transaksi yang dilakukan oleh customer dan anggota.

9. Proses 9.0 $\mathrm{P}$ yaitu proses aktivasi atau mengaktifkan customer menjadi anggota yang akan dilakukan oleh admin.

10. Pada proses 10.0 yaitu data reseller. Terdapat alur reseller, downline, bonus, ubah harga, dan ubah background.

11. Proses 11.0 P yaitu laporan (laporan produk, laporan customer, laporan anggota, laporan penjualan dan laporan bonus).

Seluruh proses-proses pada DFD Level 0 rancang bangun web replika pada websiteecommerce yang ada di atas dapat dilihat pada Gambar 2.

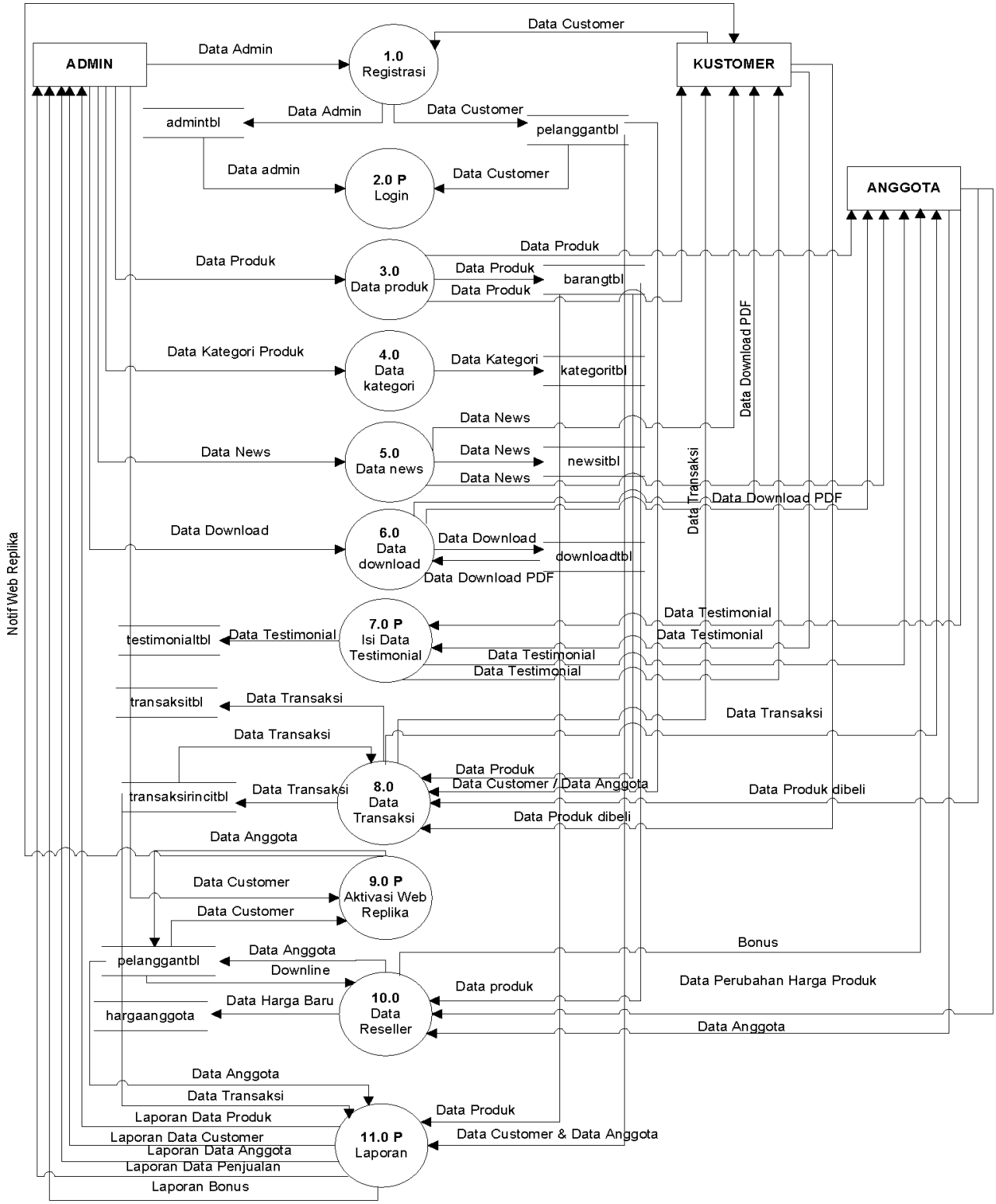

Gambar 2. DFD Level 0 Web Replika Pada WebsiteE-commerce.. 


\subsubsection{Entity Relationship Diagram (ERD)}

ERD atau Entity Relationship diagram merupakan salah satu model yang digunakan dalam mendesain database dengan tujuan menggambarkan data-data yang saling berelasi pada sebuah database. Adapun kardinalitas pemetaan yang terdapat pada ERD rancang bangun web replika pada website e-commerce sebagai berikut:

1. Hubungan satu ke satu (onetoone).

a. Satu pelanggan input satu harga anggota.

2. Hubungan satu ke banyak (oneto many).

a. Satu admininput banyak barang

b. Satuadminupload banyak data PDF.

c. Satu admininput banyak kategori.

d. Satu admininput banyak news.

e. Satu pelanggan download banyak data PDF

3. Hubungan banyak ke banyak (many to many).

a. Banyak pelanggan melakukan banyak transaksi.

b. Banyak pelanggan melakukan banyak transaksi rinci.

c. Banyak pelanggan beli banyak barang.

d. Banyak pelanggan melakukan banyak visitor.

Untuk melihat lebih jelas rancangan ERD dari aplikasi rancang bangun web replika pada websitee-commerce dapat dilihat pada Gambar 3.

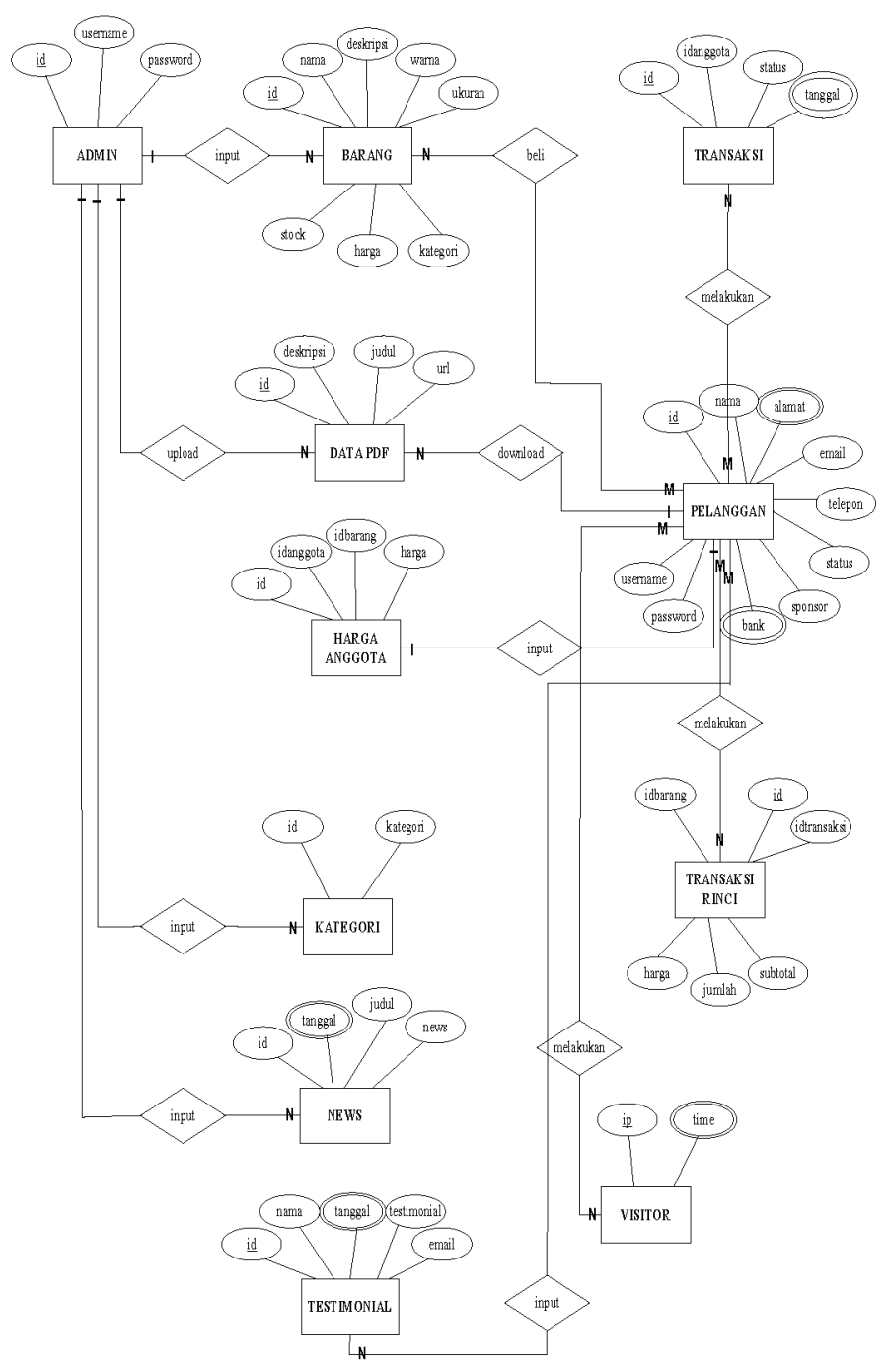


Gambar 3. ERD Rancang Bangun Web Replika Pada WebsiteE-commerce.

\section{Hasil dan Pembahasan}

\subsection{Perbedaan Web Induk Dan Web Replika}

Halaman awal web induk ini merupakan halaman pertama yang nantinya akan muncul ketika mengetikkan alamat urlonline shop stta.name:8000. Pada halaman awal web induk ini terdapat menu atas yang terdiri dari 6 menu yaitu Home, Produk, Cara Order, Download, Aboutdan Contact. Tampilan web induk dapat dilihat pada Gambar 4.

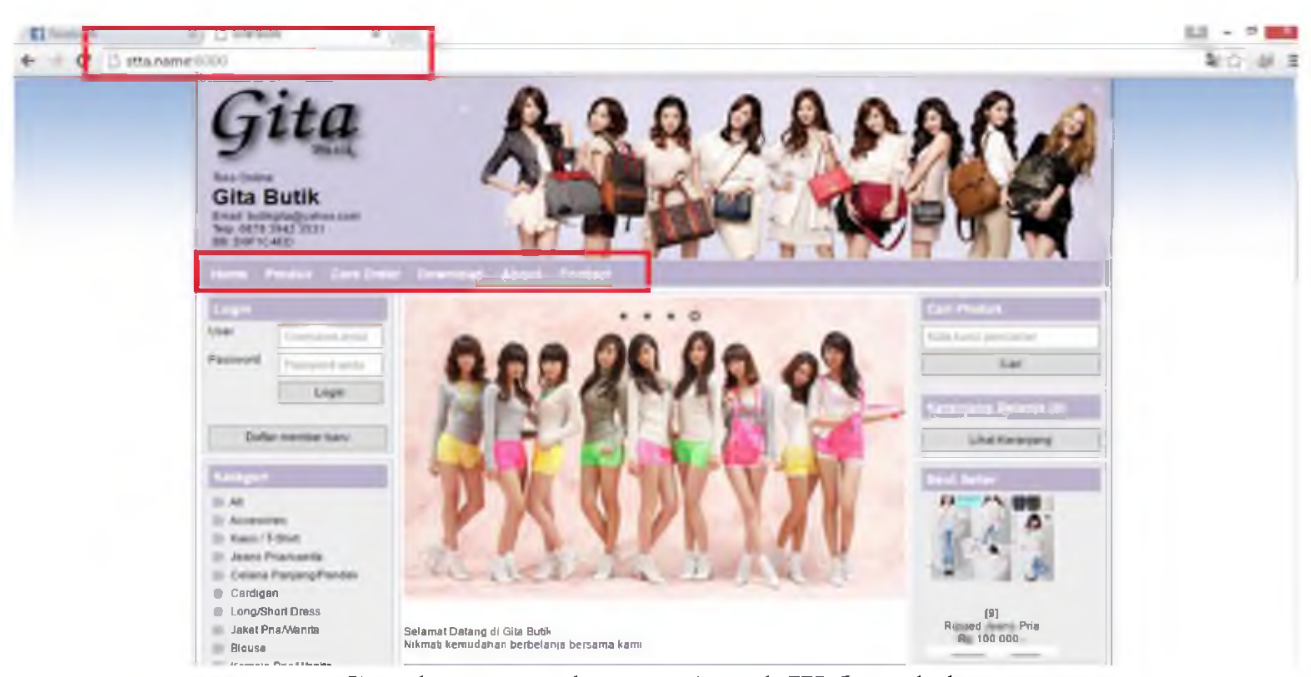

Gambar 4. Halaman Awal Web Induk.

Sedangkan, saat mendaftar web replika maka alamat url yang digunakan adalah

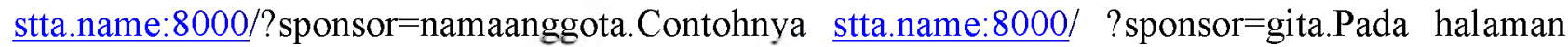
utama $w e b$ replika memiliki menu atas yang sama dengan web induk namun, yang membedakannya adalah terdapat data sponsor yang diikuti pada menu slide bar kanan. Web replika terdapat 2 jenis yaitu webreplika customer dan web replika anggota.Pada web replika customer menu atas sama persis dengan menu atas pada halaman web induk yaitu (Home, Produk, Cara Order, Download, About, Contact, logout). Sedangkan, pada web replika anggota menu atasnya terdiri dari (Home, Produk, Reseller, Harga, Downline, Bonus, Latar, Cara Order, Download, About, Contact, logout). Menu Reseller adalah tempat update data anggota dan melihat alamat web replika. Menu harga adalah tempat ubah harga produk. Menu Downline untuk melihat data downline. Menu Latar untuk merubah tampilan background latar web replika. Tampilan web replika dapat dilihat pada Gambar 5 dan Gambar 6.

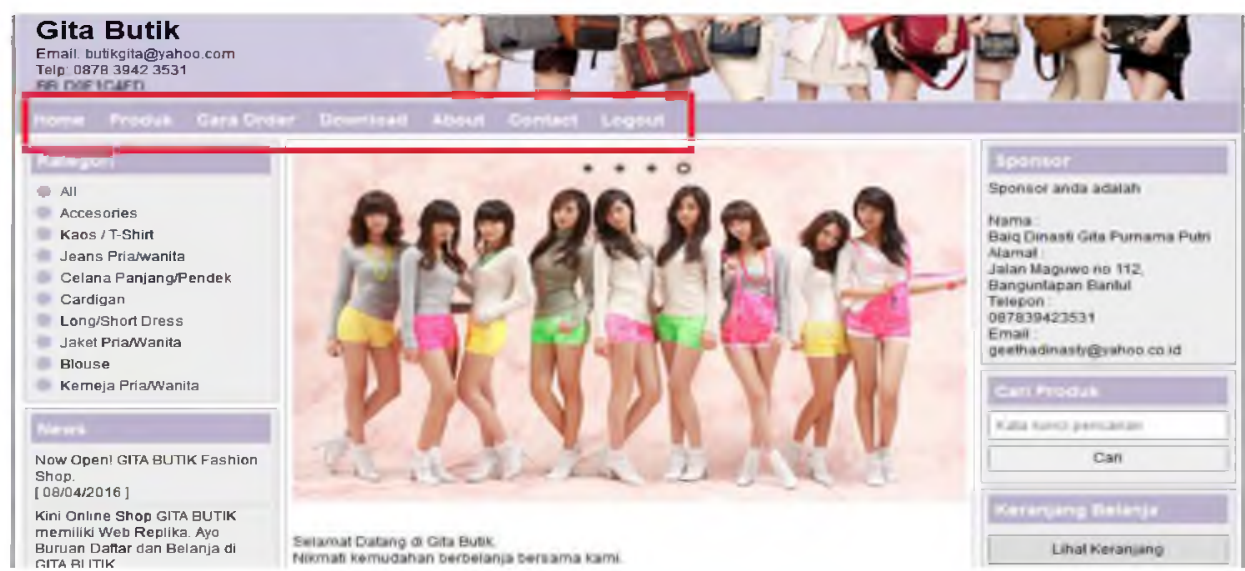

Gambar 5. Halaman Utama Web replika Customer. 


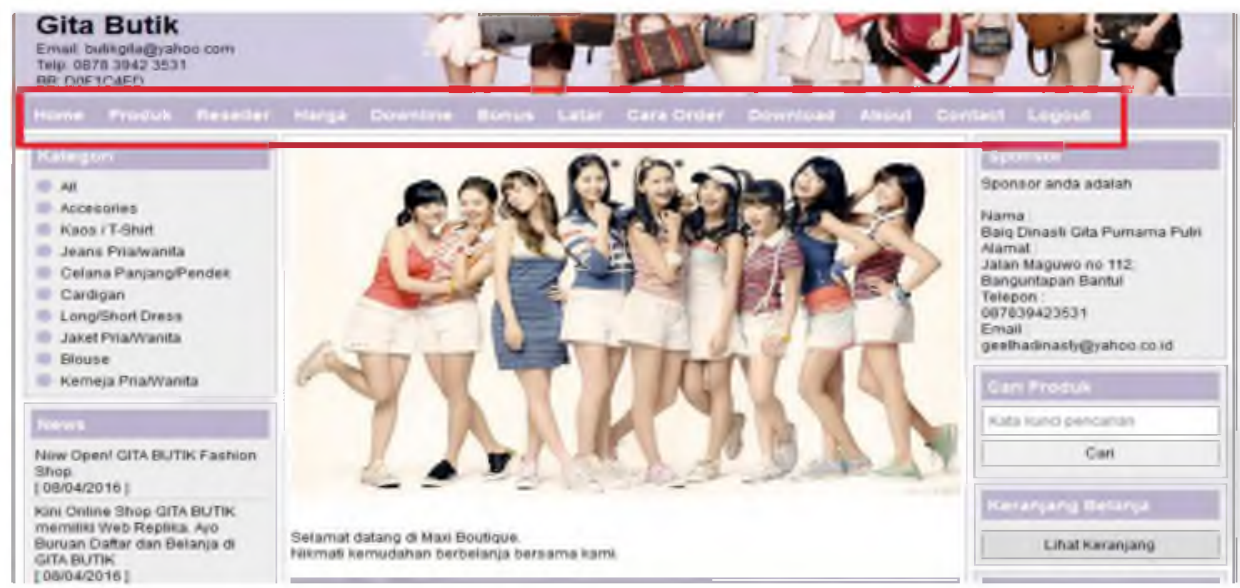

Gambar 6. Halaman Utama Web Replika Anggota.

\subsection{Hasil Uji Pengguna}

Uji pengguna dibagi menjadi 2 bagian yaitu pengujian pengetahuan web replika dan pengujian pengunaan aplikasi. Dari penyebaran kuesioner kepada 30 responden didapatkan hasil sebagai berikut:

1. Dari penyebaran kuesioner ke 30 orang didapatkan $66 \%$ orang yang suka beberlanja onlinedan hanya $38,7 \%$ saja yang mengetahui tentang web replika.Didapatkan juga persentase $36 \%$ untuk yang telah mengakses webreplika dan $36.7 \%$ saja yang dapat membedakan antara web asli dengan web replika. Kemudian yang terakhir hanya $36 \%$ yang mengetahui ciri-ciri dari web replika.Hasil pengujian pengetahuan web replika pada Gambar 7, diperoleh hasil rata-rata persentase untuk pengujian pengetahuan web replika adalah sebesar $42.7 \%$. Jika dilihat pada tabel interval penilaian maka $42.7 \%$ masuk dalam kategori Cukup. Sehingga, dapat diartikan bahwa responden sudah cukup mengetahui tentang apa itu web replika.

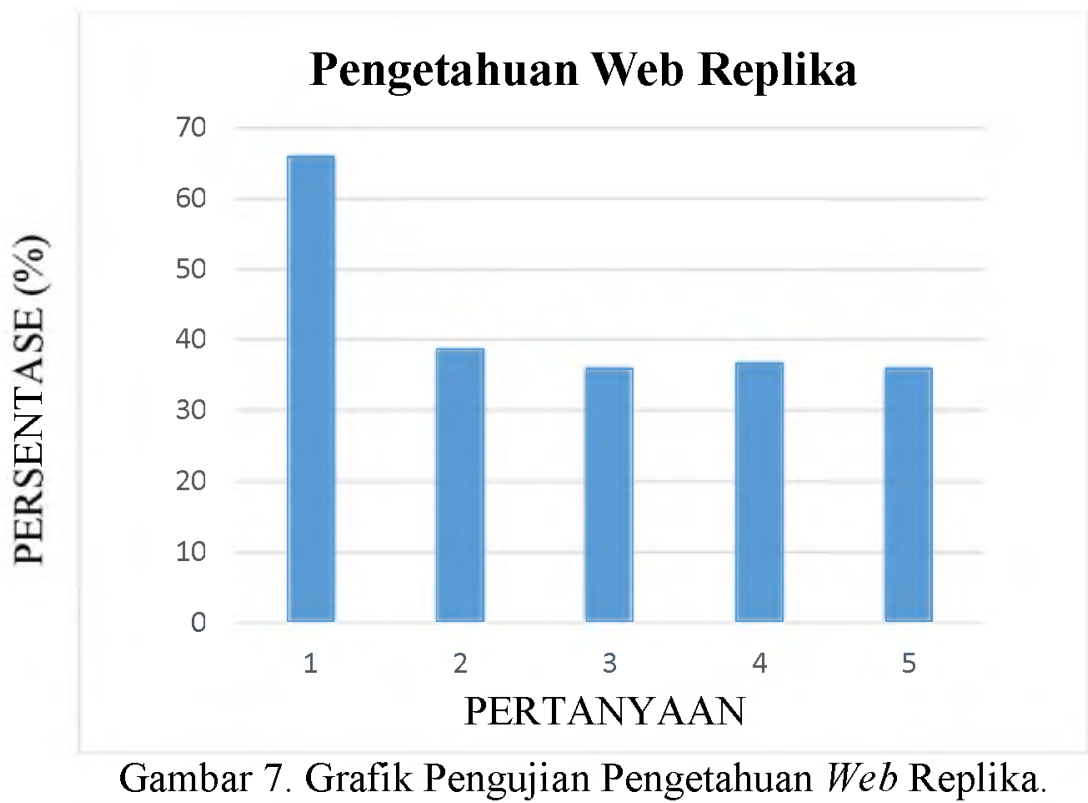

2. Hasil pengujian pengunaan aplikasi pada Gambar 8, diperoleh hasil rata-rata persentase untuk pengujian pengetahuan web replika adalah sebesar $78.5 \%$. Jika dilihat pada tabelinterval penilaian maka $78.5 \%$ masuk dalam kategori Baik. Maka dapat diartikan bahwa penggunaan aplikasi sudah baik. 


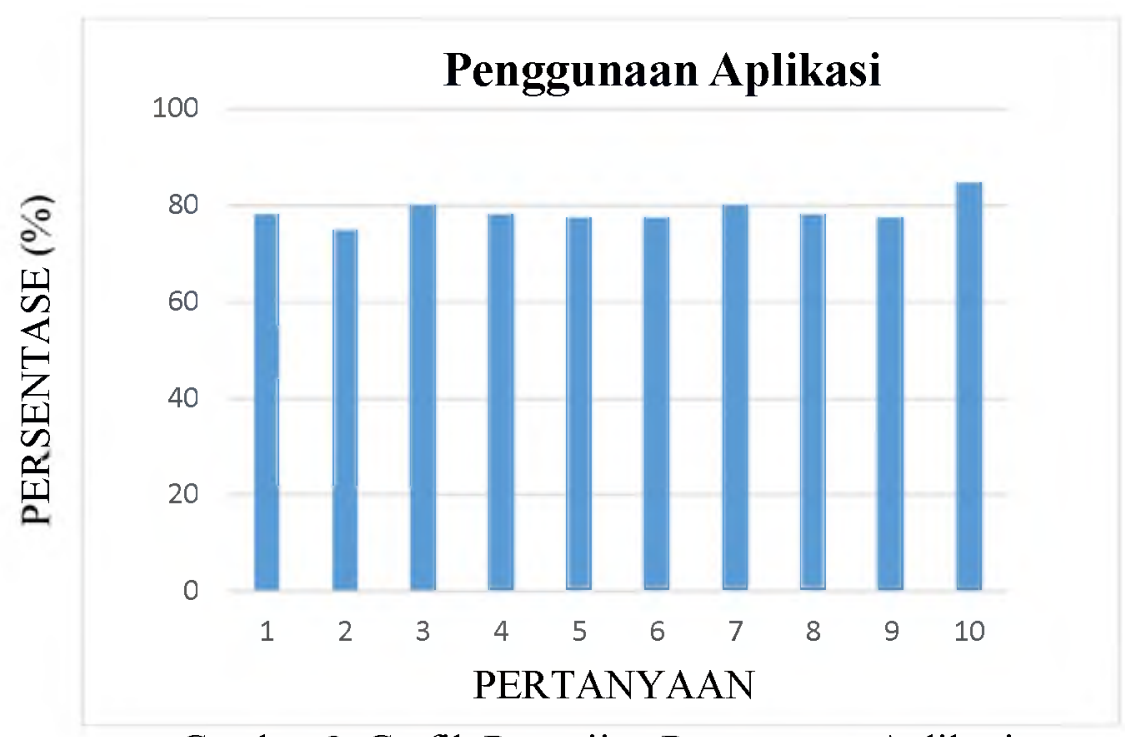

Gambar 8. Grafik Pengujian Penggunaan Aplikasi.

\section{Kesimpulan dan Saran}

\subsection{Kesimpulan}

Berdasarkan hasil dari implementasi sistem yang tedapat pada BAB IV maka adapun yang dapat disimpulkan pada penelitian ini adalah sebagai berikut :

1. Web replika dapat diterapkan pada web e-commerce dengan alamat replikanya berada dibelakang alamat induknya.

2. Pemilik website replika dapat mengubah backgroundwebsitenya dan harga jual barang yang berbeda dengan induknya.

3. Pemilik website replika dapat bonus dari website induknya ketika barang yang ditampilkan pada website replika terjual.

4. Anggota akan mendapatkan bonus dari selisih harga yang telah diubah dengan harga 1 level diatasnya baik dari web induk maupun dari sponsornya.

5. Dari hasil perhitungan kuesioner yang telah disebar kepada 30 responden didapatkan hasil pengujian pengetahuan web replika sebesar $42.7 \%$ yang berarti Cukup, dan pengunaan aplikasi sebesar $78.5 \%$ yang berarti Baik.

\subsection{Saran}

Berdasarkan kesimpulan dari sistem ini, didapatkan beberapa saran untuk pengembangan selanjutnya, sebagai berikut :

1. Rancang bangun web replika pada websitee-commerce dapat dikembangkan pada perangkat android.

2. Web replika juga dapat dikembangkan dengan fasilitas tambahan seperti dapat menambahkan produk sendiri oleh anggota diluar produk yang dijual oleh web induk.

3. Pada menu ubah background yang hanya dapat diganti dengan image format .PNG dapat dikembangkan untuk semua format gambar.

4. Anggota tidaknya hanya dapat merubah background web replika saja. Namun, dapat juga merubahtema.

\section{Daftar Pustaka}

[1] Baum, David. 1999. Business Links, Oracle Magazine, no.3, Vol.XIII, May/June, pp.36-44.

[2] Fatansyah. 1999. Basis Data. Bandung : Informatika. 
[3] Sadeli, Muhammad. 2013. Toko Baju Online Dengan PHP dan Mysql Menggunakan Adobe Dreamweaver CS 6. Palembang : Maxikom.

[4] Purbo, Ono W. dan Wahyudi, Aang Arif. 2008, Mengenal E-commerce. Jakarta : PT. Elex Media Komputindo.

[5] Tiens. 2014. Panduan Sistem Web Replika .Jurnal Bahasa Indonesia. http:/ernitiens.blogspot.co.id/p/reward.html. (Diakses 06 Mei 2015 pukul 09.00 WIB). 